\title{
A Universidade Federal da Paraíba no contexto do SINAES: a experiência do Curso de Odontologia
}

\author{
Francineide Almeida Pereira Martins*, Maria Elba Dantas Pereira de Moura** \\ * Professora do Departamento de Clínica e Odontologia Social- \\ UFPB. Membro da CPA/UFPB \\ ** Coordenadora Geral de Avaliação dos Cursos de Graduação e das \\ Instituições de Ensino Superior do INEP/MEC
}

\begin{abstract}
"Uma das principais finalidades do conhecimento é proporcionar ao homem condições e possibilidades de uma avaliação crítica do seu modo pessoal e social de viver. Assim, o conhecimento se torna uma mola propulsora de mudanças e transformações sociais. Necessário se faz, para tanto, que o sujeito cognoscente possua coragem. Caso contrário, como se opor, quando necessário, aos hábitos arraigados, às interpretações críticas da realidade, ao poder que pretende amordaçar o conhecimento, às honrarias e recompensas que, em determinadas ocasiões, funcionam como verdadeiros obstáculos na estrada da obtenção da certeza e da busca da verdade?" (LUCKESI, $2000)^{5}$
\end{abstract}

\section{RESUMO}

Este artigo relata a experiência da Universidade Federal da Paraíba-UFPB no contexto do Sistema Nacional de Avaliação do Ensino Superior-SINAES. Discute os principais resultados obtidos com a operacionalização da Auto-Avaliação Institucional e da Avaliação das Condições de Oferta do Curso de Graduação em Odontologia e do ENADE 2004. Os relatórios dessas avaliações foram gerados com base na pesquisa documental e de campo realizadas pelas Comissões de Avaliação (internas e externas), e apresentam um diagnóstico das condições organizacionais e estruturais do Curso e da Instituição. Destaca a relevância desses relatórios na elaboração do Projeto Pedagógico Institucional, no Plano de Desenvolvimento Institucional e nas atividades de operacionalização e auto-avaliação do Projeto Político Pedagógico do Curso de Odontologia.

\section{DESCRITORES}

Legislação do Ensino Superior. Avaliação Institu- cional. Avaliação dos Cursos de Graduação. Plano de Desenvolvimento Institucional.

\section{CONTEXTUALIZAÇÃO HISTÓRICA DA AVALIAÇÃo dA EDUCAÇÃo SUPERIOR BRASILEIRA}

A convivência da educação superior brasileira com processos institucionais avaliativos data de 1977, quando foi implantada a avaliação dos cursos de pósgraduação pela Coordenação de Aperfeiçoamento do Pessoal de Nível Superior-CAPES.

Somente na década de noventa, com o lançamento das bases do Programa Nacional de Avaliação Institucional das Universidades Brasileiras -PAIUB, a avaliação do ensino superior começa a se delinear, isso após várias tentativas de implantá-la, ao longo da década de 80 , e de se tornarem freqüentes, na mídia escrita e eletrônica, as críticas ao sistema de ensino superior.

Pouco tempo depois, esse programa, inspirado em documentos da Associação Nacional dos Dirigentes das Instituições Federais de Ensino Superior-ANDIFES, caracterizado por princípios emancipatórios e participativos, pela livre adesão das universidades, através da concorrência de projetos, e por ter dotação financeira própria, foi encerrado, abruptamente, pelo MEC, lançando por terra, na maioria das instituições que a ele aderiram, os esforços empreendidos para instalar, nesses meios, a cultura da avaliação.

Três anos mais tarde, em 1996, a Lei de Diretrizes e Bases da Educação-LDB preceituou a avaliação como prática para a supervisão e a regulação do Sistema Federal de Ensino Superior, atribuindo-lhe a função de realizar o monitoramento da oferta de educação superior.

A partir de então, a avaliação dos cursos de gra- 
duação e das Instituições de Educação Superior-IES começa a aparecer como um processo contínuo e renovável em função dos limites de prazos impostos pela LDB para a autorização e reconhecimento de cursos e para o credenciamento de IES, todos renovados periodicamente mediante processo regular de avaliação.

Na seqüência, o Decreto N. 2.026, de 10 de outubro de 1996, estabeleceu os procedimentos de avaliação mediante os seguintes instrumentos (BRASIL, 2004): ${ }^{1}$

a) Avaliação do desempenho individual da IES, em ensino, pesquisa e extensão;

b) Avaliação do ensino de graduação pelas condições de oferta desse ensino, pelos resultados dos exames nacionais de desempenho dos estudantes e pela avaliação da pós-graduação - esta a continuar sendo feito pelas CAPES.

Quando isso ocorreu, já estava em curso a polêmica Avaliação Nacional dos Estudantes-ENC, também conhecida como "PROVÃO", cuja recente publicação dos primeiros resultados havia gerado uma torrente de críticas e de protestos que a acompanhariam até a sua extinção.

Note-se que essas avaliações, propostas pelo Estado, findaram por tomar uma feição de instrumento de poder político, aplicado com fins que contrariavam os propósitos e as ações emancipatórias propugnadas no PAIUB.

No marco dessas contradições, a Conferência Mundial sobre Educação Superior realizada pela UNESCO, em Paris, no ano de 1998, realizava a discussão dos sistemas e instituições de educação superior na América Latina, apontando sérios problemas que comprometiam a qualidade, a pertinência e a equidade de suas contribuições às sociedades que os sustentavam.

A esse propósito, Dias Sobrinho (1998) ${ }^{4}$ já pontuava que a qualidade da educação superior está associada a três elementos:

- A qualidade é um conceito relativo a um determinado padrão de referência adotado, o que significa ser possível, num universo de IES situadas em contextos socioeconômicos diferentes, configurarem-se diferentes padrões de qualidade acadêmica;

- A qualidade implica na necessidade de se estabelecer um sistema valorativo, dentre os vários sistemas possíveis num determinado contexto societário, a fim de evitar os riscos de transformar a qualidade numa utopia de referência, desvincula- da de um determinado meio social;

- Para emitir um juízo de valor sobre a qualidade do ensino superior é indispensável estabelecer-se elementos comparativos (como, por exemplo, a relação entre avaliação externa e avaliação interna de um determinado curso de graduação).

Nesse contexto diversificado de concepções filosóficas e políticas, emergiu o Plano Nacional de Educação (PNE), editado por meio da Lei N. 10.172, de 2001, que dispõe no seu art. $4^{\circ}$, que a União "instituirá o Sistema Nacional de Avaliação e estabelecerá os mecanismos necessários ao acompanhamento das metas constantes do Plano Nacional de Educação"

Para atender a essas determinações legais, foi publicado o Decreto de N ${ }^{\circ}$. 3.860, em julho de 2001, apresentando, em caráter definitivo, a partir de uma orientação política neoliberal, as bases conceituais e metodológicas para a avaliação da educação superior.

Porém, como instrumento de investigação e sendo, também, uma construção sócio-histórico-cultural, a avaliação permite a coexistência de concepções diferenciadas e antagônicas, estabelecendo o contraditório. Esse fato, aliado a um caldo de cultura favorável, terminou por fazer germinar novas concepções de avaliação impregnadas das trocas e das influências de parte a parte.

Finalmente, emergindo de um processo democrático e participativo coordenado pelo MEC, em 14 de abril de 2004, foi promulgada a Lei n. 10.861, que instituiu o Sistema Nacional de Avaliação da Educação Superior - SINAES, com o objetivo de assegurar processo nacional de avaliação das IES, dos cursos de graduação e do desempenho acadêmico de seus estudantes, atendendo ao art. $9^{\circ}$, VI, VIII e IX da LDB/96 (BRASIL, 2004). ${ }^{2}$

Essa avaliação, concebida para ser um processo que "efetivamente vincula a dimensão formativa a um projeto de sociedade comprometido com a igualdade e a justiça social", está fundamentada nos seguintes princípios, segundo as Diretrizes para a Avaliação das Instituições de Educação Superior (MEC/ CONAES, 2004): $:$,

- Responsabilidade social com a qualidade da educação superior;

- Reconhecimento à diversidade do sistema;

- Respeito à identidade, à missão e à história das instituições;

- Globalidade institucional, pela utilização de um conjunto significativo de indicadores considerados em sua relação orgânica; 
- Continuidade do processo avaliativo como instrumento de política educacional para cada instituição e para o sistema da educação superior em seu conjunto.

OSINAES, portanto, expressa importante mudança no sentido de superar uma lógica de avaliação fragmentária e classificatória porque estabelece maior abrangência e integra diferentes procedimentos avaliativos comprometidos com a qualidade acadêmica.

Consegue, assim, avançar para além da verificação realizada verticalmente (do MEC para as instituições e cursos), ao gerar um processo de avaliação compreensivo e pedagógico que parte da IES e a ela retorna, passando pela ação mediadora do poder público.

Outra vertente positiva desse processo advém de sua forma de operacionalização, pelo Instituto Nacional de Estudos e Pesquisas Educacionais Anísio Teixeira, segundo as diretrizes da Comissão Nacional de Avaliação da Educação Superior-CONAES. Esse modelo operacional propicia uma melhor integração da avaliação com as políticas de Estado, uma utilização mais eficiente dos resultados nos processos regulatórios, com esperados reflexos sobre a melhoria da qualidade da educação superior brasileira, em seu conjunto.

\section{AVALIAÇÃO INSTITUCIONAL NA UFPB: A EXECuÇÃo do PROJETO AVALIES}

O projeto Avalies-UFPB teve início em 2004, e foi elaborado por 11 comissões (CpDs) constituídas de discentes, docentes, funcionários técnico-administrativos e membros da comunidade externa, após a realização de sete seminários de divulgação e sensibilização da comunidade universitária, com vistas a obter múltiplas e diferenciadas contribuições A metodologia do projeto previu quatro etapas para o seu desenvolvimento:

- Pesquisa documental;

- Pesquisa de campo, para suprir possíveis deficiências documentais;

- Análise e crítica dos documentos e dados;

- Elaboração e divulgação do relatório final.

Concluído em dezembro desse mesmo ano, o projeto de Auto-avaliação Institucional da UFPB foi encaminhado à apreciação da CONAES, vindo a receber o conceito máximo dessa comissão.

Em maio de 2005, quando as comissões de avaliação, coordenadas pela Comissão Própria de Avalia-
ção-CPA e pela Comissão Executiva de Avaliação Institucional-CEAI, tiveram acesso aos documentos indispensáveis à realização da pesquisa documental, já se preparavam para a fase da pesquisa de campo, tendo elaborado os seus instrumentos de coleta de dados.

Inicialmente, pensou-se em disponibilizar esses instrumentos on-line, objetivando-se conseguir uma participação mais ampla da comunidade acadêmica. Verificada, porém, a impossibilidade institucional de concretizar essa ação em tempo compatível com o demando para a aplicação dos questionários eletrônicos, as comissões optaram por realizar a pesquisa de campo com o emprego dos tradicionais formulários impressos.

Nessa fase, foram realizadas as "caravanas de avaliação”, para a aplicação dos instrumentos de coleta de dados nos nove centros da UFPB. Os membros da Comissão Executiva de Avaliação Institucional-CEAI compareciam em conjunto para aplicar os questionários e realizar as entrevistas, demonstrando unidade, integração e compromisso com o processo avaliativo.

Representantes do centro visitado se responsabilizavam pela preparação do ambiente nos Centros e o convite de participação à comunidade. Vale ressaltar, o apoio incondicional dos diretores dos centros à auto-avaliação institucional e às comissões de avaliação mostrando-se bastante receptivos e grandes colaboradores.

Uma vertente metodológica que se revelou das mais eficazes foi trabalhar a auto-avaliação de forma integrada com a avaliação das condições dos cursos de graduação (entre o final de 2004 e o início de 2006, foram avaliados 14 cursos, de um total de 43) e com o ENADE 2005 - 2006.

Essa nova frente de atuação produziu excelentes resultados para a avaliação institucional e, também, para a administração superior: as informações contidas nos diversos relatórios e documentos produzidos pela CPA/CEAI, sobre o ENADE e a AVG, foram de grande valia àquele momento em que estavam sendo elaborados o Projeto Pedagógico Institucional e o Plano de Desenvolvimento Institucional.

A consolidação do relatório final, na sua versão preliminar, foi realizada de forma semelhante à adotada para o projeto AVALIES-UFPB: reuniram-se os relatórios produzidos pelas onze comissões, realizouse a análise do seu conteúdo, e, obtido o consenso sobre o texto completo, finalizou-se o documento.

Em seguida, o relatório foi reproduzido e encaminhado para a apreciação da Reitoria, Conselhos Su- 
periores, Direções de Centro, Coordenações de Curso e Chefias Departamentais, estabelecendo-se um prazo para o recebimento, por escrito, de adendos, correções e sugestões.

Recebidas as contribuições, foram apreciadas pelas comissões e, quando houve consenso, incluídas ao texto do relatório. Concluídos os ajustes, o mesmo foi impresso, dando-se-lhe ampla divulgação (MOURA et al., 2006) ${ }^{8}$

\section{AVALIAÇÃO dAS CONDIÇÕES DE OFERTA DO CURSO DE ODONTOLOGIA DA UFPB}

A experiência de avaliação do Curso de Odontologia da UFPB remete a 2002, quando da criação pela CPME/PRG da Comissão de Avaliação da Graduação, que em caráter experimental instituiu a avaliação de desempenho docente, na óptica do discente, conferindo ao aluno relevância, credibilidade e parceria no processo avaliatório. Esse instrumento, aplicado nos períodos letivos 2002.2 2003.1 e 2003.2, aferiu ao Curso de Odontologia um Índice de Desempenho Docente médio de 7.0, em uma escala de 0 a 10. Esperava-se que os resultados dessa avaliação subsidiassem políticas de melhoria do ensino da graduação no âmbito da Instituição. No entanto, verificou-se a descontinuidade de uma ação transformadora de avaliação do processo ensino-aprendizagem que contribuía para a emancipação do aluno, como sujeito da ação, e aos docentes uma análise crítica do seu papel como educador.

A criação do SINAES como política de avaliação superior do MEC, inovou pela sua abrangência, profundidade e metodologia ao integrar a Auto-avaliação, a Avaliação das Condições de Graduação-ACG e o Exame Nacional de Desempenho dos EstudantesENADE, e instituiu uma gama de informações diversificadas e extremamente relevantes para a avaliação e o planejamento acadêmico da IES, em particular, da UFPB.

No contexto do Curso de Odontologia, o processo de avaliação conquistou adesão e a participação responsável dos gestores, técnicos e docentes com a criação de uma comissão interna de avaliação, que foi subdividida em três grupos, segundo as dimensões a serem analisadas:

- organização didático-pedagógica,

- corpo docente e

- instalações.

Cada grupo foi responsável pela pesquisa documental das respectivas dimensões, análise e compro- vação das informações encaminhadas à coordenação. Essa fase, considerada a "anamnese", detectou as potencialidades e fragilidades que fomentaram o diagnóstico do curso.

Do ponto de vista da organização didático pedagógica, o curso tinha como potencialidade um projeto político pedagógico recém implantado e caminhando paralelamente com o currículo antigo. Essa multiplicidade de componentes curriculares sobrecarregava os docentes e gerava graus diferenciados de satisfação entre os estudantes. O projeto pedagógico inovou ao contemplar no currículo componentes curriculares como estágios supervisionados e seminários de integração do primeiro ao último período do curso, o Trabalho de Conclusão do Curso -TCC, a criação de novas clínicas integradas, além da existente no final do curso, e o enfoque em atividades práticas e na saúde coletiva. Dá-se como certo que esse novo projeto contribuiu fortemente para o conceito Muito Bom da dimensão didático-pedagógica, quando da avaliação in loco.

Todavia, alguns aspectos deixaram a desejar e foram apontados pela comissão de avaliação in loco: inexistência de mecanismos de apoio institucional pedagógico/psicopedagógico e de nivelamento do grau de conhecimentos adquiridos pelos alunos, oriundos de realidades diversificadas (ensino médio em escolas públicas, privadas, condições diversas); indefinição de uma política institucional de acompanhamento dos egressos e o escasso apoio a eventos, fragilizavam a gestão acadêmica. Esses aspectos também foram pontuados por Moura, Queiroz (2007) ${ }^{9}$

A dimensão corpo docente apresentou como principal deficiência a desatualização do currículo dos professores. Muitas das atividades de ensino, pesquisa e extensão e artigos publicados em periódicos científicos deixaram de ser pontuados. A existência de um programa de pós-graduação (mestrado e doutorado) no curso, onde são desenvolvidos projetos integrados com alunos da graduação, e o quantitativo de qualificação dos docentes, notoriamente contribuiram para a atribuição do conceito Muito Bom dessa dimensão.

A análise da dimensão instalações revelou deficiências nas instalações físicas de alguns dos laboratórios didáticos e das clínicas, e na manutenção preventiva de equipamentos. Essas clínicas e laboratórios foram avaliados com conceitos que oscilaram entre muito bom e insatisfatório. Até então, inexistia um plano institucional de expansão das instalações físicas e de aquisição e manutenção de instrumentos e equi- 
pamentos, o que contribuiu para o conceito Regular dessa dimensão.

Outras fragilidades detectadas referiam-se ao acervo limitado e pouco atualizado da biblioteca central, e à ineficácia do sistema de segurança do campus, diagnóstico semelhante foi relatado por Moura, Queiroz $(2007)^{9}$

Deve-se ressaltar que esse relatório subsidiou o subseqüente Planejamento de Desenvolvimento Institucional da UFPB e, tão logo ele entrou na fase de execução, aquelas deficiências começaram a ser sanadas.

\section{EXAME NACIONAL DE DESEMPENHO DOS ESTUDANTES - ENADE. A EXPERIÊNCIA DO CURSO DE ODONTOLOGIA DA UFPB}

O Exame Nacional de Desempenho do Estudante-ENADE representa um avanço na sistematização dos instrumentos avaliatórios por aferir o desempenho dos estudantes aos conteúdos programáticos propostos nas Diretrizes Curriculares dos cursos de graduação, às suas habilidades e competências, inseridos às realidade nacional, mundial e demais áreas do conhecimento.

No contexto do ENADE/2004, o Curso de Odontologia destacou-se por obter o desempenho máximo (5.0), tendo sido o único da UFPB a atingir esse patamar de excelência. Pode-se atribuir esse resultado a influência de vários fatores, entre os quais, a operacionalização do Projeto Político Pedagógico do curso, que traçou um novo perfil dos egressos, direcionou objetivos firmados na ética e na realidade sócio-econômico-cultural da comunidade, inovou propostas metodológicas e conteúdos programáticos, além da gestão acadêmica interagir continuamente com a CPME/UFPB.

Secundariamente, as ações de sensibilização desenvolvidas pela coordenação do curso, pela CPA e pela Coordenação para Melhoria do Ensino da PróReitoria de Graduação. Destinada aos docentes e discentes do curso, essas ações ocorreram sob a forma de oficinas, divulgação do Manual e discussão da legislação pertinente, culminando com um ciclo de debates em áreas relevantes, dentre as quais a saúde coletiva e atualização clínica.

O relatório do ENADE-2004, divulgado posteriormente pelo INEP, possibilitou ao Curso uma análise crítica e abrangente do seu projeto de curso, das suas instalações e do compromisso docente e subsidiou, posteriormente, a auto-avaliação do curso.

\section{DO APRENDIZADO À EXPERIÊNCIA}

Na Universidade Federal da Paraíba, o processo de avaliação representou uma experiência inédita $\mathrm{e}$ exitosa na história desta instituição, com a superação de obstáculos, doses elevadas de dedicação, persistência e competência.

Possibilitou, principalmente, a compreensão sobre a indissociabilidade entre avaliação e planejamento. Ao integrar-se a Auto-avaliação institucional, o Exame Nacional de Desempenho dos EstudantesENADE e a Avaliação das Condições de Graduação - ACG, teve-se acesso a informações diversificadas, mas conectadas entre si, capazes de subsidiar as políticas institucionais de melhoria de ensino.

A avaliação deve, portanto, constituir-se prática rotineira nas instituições superiores, cuja eficácia está condicionada a ações conseqüentes, coordenadas e permanentes que garantam a manutenção, o monitoramento e a atualização contínua dos bancos de dados gerados na auto-avaliação, e provoque a sensibilização permanente da comunidade acadêmica.

No entanto, a execução desse processo necessita de recursos financeiros que garantam as condições estruturais, assessoria qualificada e uma gestão direcionada para o crescimento e a consolidação da Instituição.

Assim, no âmbito governamental, há que se aperfeiçoar políticas de incentivo à disseminação da cultura da avaliação, viabilizando a implantação de programas específicos de financiamento, por exemplo:

- bolsas de avaliação para os alunos atuarem em projetos de avaliação;

- permitir a aquisição de equipamentos e a contratação de serviços para as CPAs e

- estimular a formação continuada de recursos humanos para a avaliação.

A participação efetiva da gestora acadêmica do Curso na elaboração do Projeto Político Pedagógico do Curso, na Auto-Avaliação Institucional, como membro da CPA/CEAI/UFPB- coordenadora da Dimensão 2-A Política para o Ensino, a Pesquisa, a Extensão e Normas Operacionais; a participação em Oficinas Pedagógicas, Encontro de Capacitação de Gestores Acadêmicos e eventos relacionados a políticas de ensino, como a ABENO, fortaleceu o aprendizado e o aprofundamento em processos avaliatórios.

Finalizamos, referenciando a contextualização do SINAES pela Comissão Especial de Avaliação da Educação Superior: 
"Uma visão abrangente dos processos avaliativos sem dissociar estes da necessária regulação do Estado para fomentar e supervisionar o sistema em seu conjunto, mas também reconhece a importância de uma política capaz de refundar a missão pública do sistema de educação brasileiro, respeitando sua diversidade, mas tornando-o compatível com as exigências de qualidade, relevância social e autonomia” (CEA, 2004): ${ }^{3}$

\section{ABSTRACT}

The Federal University of Paraíba in the context of the National Evaluation System of Higher

Education (SINAES): the dentistry course experience

This article deals with the experience of the Federal University of Paraíba-UFPB in the context of the National Evaluation System of Higher Education SINAES. It discusses the main results obtained in applying the Institutional Self-Evaluation tool that considers the conditions offered by the Dentistry Course and the ENADE-2004. The reports from these evaluations were based on document research and on field work performed by internal and external Commissions of Evaluation. A diagnosis is presented of both the organizational and structural status of the course and of the Institution. The data point out the relevance of these reports in drawing up the Institutional Teaching Project, in the Institutional Development Plan and in activities for implementing and developing the self-evaluation of the Political Teaching Project of the Dentistry Course.

\section{DESCRIPTORS}

Higher Education Legislation. Institutional Evaluation. Evaluation Undergraduate Course. Institutional Development Plan.

\section{REFERÊNCIAS}

1. Brasil. Decreto-Lei n.10.861, de 14 de abril de 2004. Institui o Sistema Nacional de Educação Superior - SINAES e dá outras providências; 2004.

2. Portaria n. 2.501, de 9 de julho de 2004. Regulamenta os procedimentos de avaliação do Sistema Nacional de Avaliação da Educação Superior (SINAES), instituída na Lei n. 10.861 de 14 de abril de 2004.

3. Comissão Especial de Avaliação da Educação Superior-Brasil. Sistema Nacional de Avaliação da Educação Superior SINAES: bases para uma nova proposta da educação superior. Avaliação: revista da Rede de Avaliação Institucional da Educação Superior, Campinas; 2004.9(1):9-111, mar.
4. Dias Sobrinho, J. Funcionamento e modos sociais de avaliação institucional. Avaliação. Revista da Rede de Avaliação Institucional da Educação Superior, Campinas; 1998.3(2):65-76.

5. Luckesi CC et. al. Fazer universidade: uma proposta metodológica. $11^{\mathrm{a}} \mathrm{ed}$. São Paulo:Cortez; 2000. 232p.

6. Ministério da Educação/MEC. Instituto Nacional de Estudos e Pesquisas Educacionais Anísio Teixeira. Comissão Nacional de Avaliação da Educação Superior. Roteiro de auto-avaliação institucional. Brasília: Editoria, 2004

7. .Instituto Nacional de Estudos e Pesquisas Educacionais Anísio Teixeira. Comissão Nacional de Avaliação da Educação Superior. Instrumento de Avaliação Institucional Externa. Brasília: Editoria, 2006.

8. Moura, Med de et al.li. O Sinaes na UFPB: Relato das experiências da Comissão Própria de Avaliação e da Comissão Executiva de Avaliação Institucional da Universidade Federal da Paraíba. João Pessoa:Manufatura; 2006. ISBN 85-87939-78-5, $121 \mathrm{pg}$.

9. Moura, ME, Taigy, AC. A experiência da Universidade Federal da Paraíba-UFPB no contexto do Sistema Nacional de Avaliação da Educação Superior-SINAES. Edu Pro: C e T. Brasília; 2(1):209-18, jul-dez, 2007.
Recebido em 20/08/2008 Aceito em 25/11/2008 